\title{
Ghrelin action in the brain controls adipocyte metabolism
}

\author{
Claudia Theander-Carrillo, ${ }^{1}$ Petra Wiedmer, ${ }^{2}$ Philippe Cettour-Rose, ${ }^{1}$ Ruben Nogueiras, ${ }^{2}$ \\ Diego Perez-Tilve, ${ }^{3}$ Paul Pfluger, ${ }^{3}$ Tamara R. Castaneda, ${ }^{3}$ Patrick Muzzin, ${ }^{4}$ Annette Schürmann, ${ }^{2}$ \\ Ildiko Szanto, 4,5 Matthias H. Tschöp,,3 and Françoise Rohner-Jeanrenaud'1
}

\begin{abstract}
${ }^{1}$ Laboratory of Metabolism, Division of Endocrinology, Diabetology, and Nutrition, Department of Internal Medicine, Faculty of Medicine, University of Geneva, Geneva, Switzerland. 'Department of Pharmacology, German Institute of Human Nutrition Potsdam-Rehbrucke, Nuthetal, Germany. 3Department of Psychiatry, Obesity Research Center, University of Cincinnati, Cincinnati, Ohio, USA. 4Department of Cell Physiology and Metabolism, Faculty of Medicine, and ${ }^{5}$ Department of Rehabilitation and Geriatrics, University of Geneva School of Medicine, Geneva, Switzerland.
\end{abstract}

\begin{abstract}
Many homeostatic processes, including appetite and food intake, are controlled by neuroendocrine circuits involving the CNS. The CNS also directly regulates adipocyte metabolism, as we have shown here by examining central action of the orexigenic hormone ghrelin. Chronic central ghrelin infusion resulted in increases in the glucose utilization rate of white and brown adipose tissue without affecting skeletal muscle. In white adipocytes, mRNA expression of various fat storage-promoting enzymes such as lipoprotein lipase, acetylCoA carboxylase $\alpha$, fatty acid synthase, and stearoyl-CoA desaturase-1 was markedly increased, while that of the rate-limiting step in fat oxidation, carnitine palmitoyl transferase-1 $\alpha$, was decreased. In brown adipocytes, central ghrelin infusion resulted in lowered expression of the thermogenesis-related mitochondrial uncoupling proteins 1 and 3. These ghrelin effects were dose dependent, occurred independently from ghrelin-induced hyperphagia, and seemed to be mediated by the sympathetic nervous system. Additionally, the expression of some fat storage enzymes was decreased in ghrelin-deficient mice, which led us to conclude that central ghrelin is of physiological relevance in the control of cell metabolism in adipose tissue. These results unravel the existence of what we believe to be a new CNS-based neuroendocrine circuit regulating metabolic homeostasis of adipose tissue.
\end{abstract}

\section{Introduction}

Neuroendocrine circuits within the CNS that are known to regulate appetite and food intake have also been shown to be involved in the control of peripheral metabolism and thermogenesis. A recent series of elegant studies demonstrates that some of the hypothalamic circuits regulating energy balance also specifically sense macronutrient availability (1-3), thereby triggering efferent signals that adjust peripheral homeostatic processes, such as glucose and lipid metabolism (4-6). The hypothalamic melanocortin system, including the neuropeptides agouti-related protein (AgRP) and $\alpha$-melanocyte-stimulating hormone, is one of the circuits involved in the CNS control of peripheral glucose homeostasis (7). Hypothalamic neuropeptide Y (NPY) also affects peripheral glucose and lipid metabolism $(8,9)$. Both the melanocortin system and NPY are known hypothalamic targets of the gastrointestinal hormone and putative neuropeptide ghrelin (10-18).

Apart from its role as a growth hormone secretagogue, exogenous ghrelin administration causes a positive energy balance and increases body weight when administered pharmacologically (10, 19,20). A physiological role for endogenous ghrelin is suggested by the fact that genetic deletion of ghrelin or its only known receptor results in decreased susceptibility to high-fat diet-induced obesity

Nonstandard abbreviations used: ACC, acetyl-CoA carboxylase $\alpha$; BAT, brown adipose tissue; CPT- $1 \alpha$, carnitine palmitoyl transferase- $1 \alpha$; FAS, fatty acid synthase; ghrelin-ad lib, ghrelin-infused, ad libitum-fed; ghrelin-pf, ghrelin-infused, pair-fed to controls; LPL, lipoprotein lipase; NPY, neuropeptide Y; RQ, respiratory quotient; SCD1, stearoyl-CoA desaturase-1; TG, triglyceride; TKO, triple $\beta_{1^{-}}, \beta_{2^{-}}$, and $\beta_{3}$-adrenoceptor knockout; UCP, uncoupling protein; WAT, white adipose tissue.

Conflict of interest: The authors have declared that no conflict of interest exists.

Citation for this article: J. Clin. Invest. 116:1983-1993 (2006). doi:10.1172/JCI25811.
$(21,22)$. This effect was observed despite the simultaneous deletion of the recently discovered ghrelin-associated satiety factor, obestatin (23), in these knockout mice. However, the phenotype of ghrelin gene-disrupted mice only becomes apparent upon chronic exposure to a high-fat diet, indicating a possibly impaired ability to store excess dietary fat in the absence of ghrelin action.

Ghrelin synthesis and secretion are regulated by the nutritional state (24-26). Thus food intake as well as the administration of glucose or other nutrients decreases circulating ghrelin levels, while caloric restriction or food deprivation increases these levels $(19,27,28)$. The extent and functional relevance of brain-derived ghrelin still needs to be clarified $(15-18,29)$. However, the orexigenic and adipogenic effects of centrally administered ghrelin are potent and consistent $(10,19,30)$.

In the present study we investigated whether central ghrelin influences peripheral metabolism and whether these effects are dependent on its orexigenic action. More specifically, the aims of our study were to determine the effects of central ghrelin administration on insulin sensitivity in peripheral tissues, lipid metabolism in white adipose tissue (WAT), and thermogenesis-related processes in brown adipose tissue (BAT). Other aims were to propose a possible mechanism for such central effects of ghrelin on peripheral cell metabolism and to determine the potential relevance of such effects for endogenous ghrelin.

We demonstrate here that central ghrelin increased food intake and independently regulated adipocyte metabolism. In white adipocytes it favored glucose and triglyceride (TG) uptake, increased lipogenesis, and inhibited lipid oxidation. In brown adipocytes icv ghrelin decreased the expression of uncoupling proteins (UCPs), which usually contribute to energy dissipation. These ghrelin effects were 

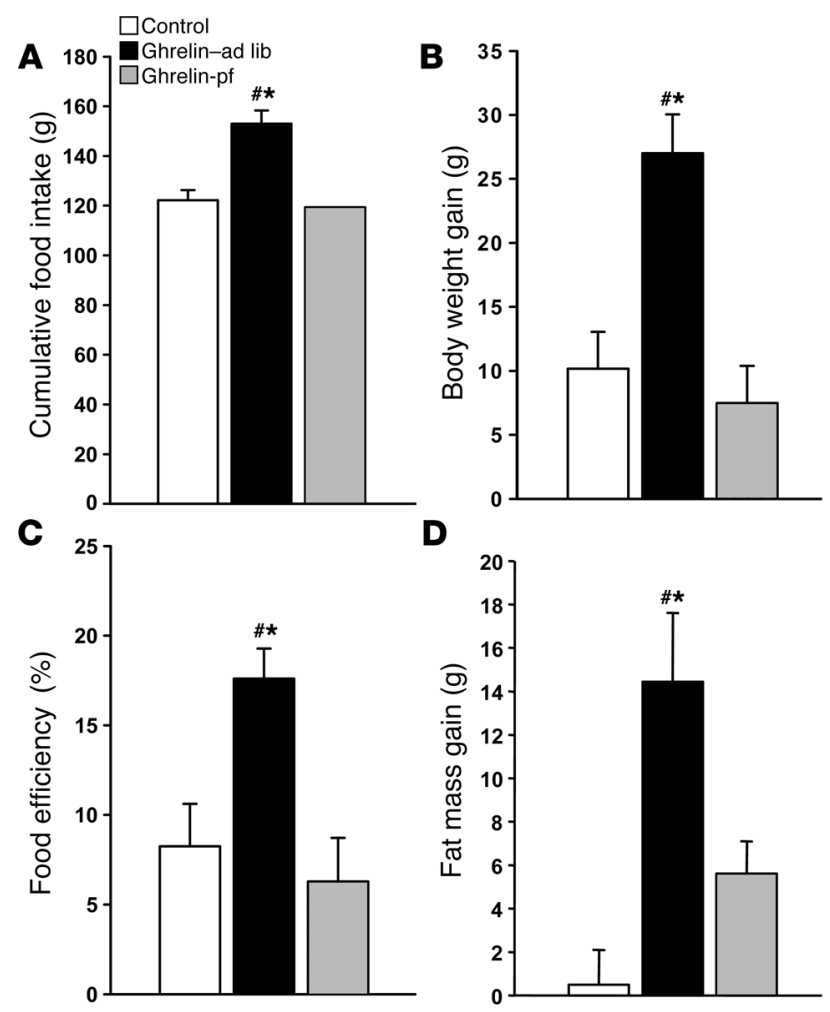

D

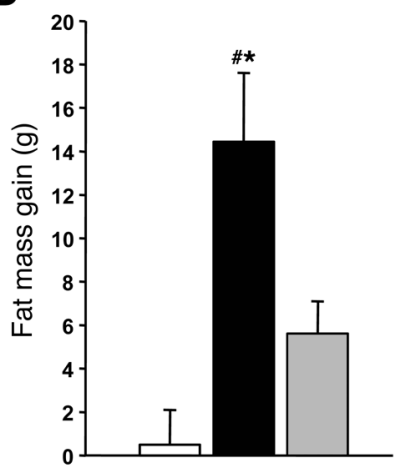

dose dependent and seemed to be mediated by the sympathetic nervous system. We additionally observed that the expression of some fat storage enzymes was decreased in ghrelin-deficient mice.

\section{Results}

Effects on energy balance. Chronic icv ghrelin infusion $(2.5 \mathrm{nmol} / \mathrm{d}$ for 6 days) increased food intake in ad libitum-fed rats (ghrelin-ad lib) compared with icv saline-infused controls (Figure 1A). A second control group consisted of icv ghrelin-infused animals that were pair-fed to the food intake of the saline-infused controls (ghrelin-pf). Body weight gain of icv ghrelin-ad lib rats was significantly higher than that of both the control and the ghrelin-pf groups (Figure 1B). Ghrelin treatment increased food efficiency, calculated as the ratio of body weight gain to cumulative food intake measured, during the 6-day experimental period (Figure 1C). The increase in body weight in icv ghrelin-infused rats was related to a higher fat mass gain, as determined by NMR imaging (Figure 1D), without any change in lean body mass (data not shown). Indirect calorimetry was used to determine whether changes in energy expenditure also contribute to the ghrelin-induced weight gain. Chronic icv ghrelin treatment did not alter total energy expenditure or spontaneous physical activity, but resulted in a significant increase in the respiratory quotient (RQ), indicative of elevated fat deposition (Table 1).

Icv ghrelin administration resulted in increased plasma levels of bioactive, octanoylated ghrelin in ghrelin-ad lib rats, but not in the ghrelin-pf group, which received the identical dose of icv ghrelin (Table 2). Gastric ghrelin mRNA expression was, however, similar in all groups of animals and did not increase with icv ghrelin administration (data not shown). Central ghrelin infusion did not affect plasma glucose, insulin, corticosterone, leptin, or FFA levels. Plasma TG concentrations were lower in ghrelin-infused rats than in controls, consistent with an increased rate of TG clearance (Table 2).

\section{Figure 1}

Effect of a 6-day icv ghrelin infusion $(2.5 \mathrm{nmol} / \mathrm{d})$ on cumulative food intake (A), body weight gain (B), food efficiency $(\mathbf{C})$, and fat mass gain (D). Food efficiency was calculated as the ratio between body weight gain over the 6-day experimental period and cumulative food intake and was expressed as a percentage. Body fat was determined by nuclear magnetic resonance imaging. Values are mean \pm SEM of 6-7 animals per group. ${ }^{*} P<0.05$ versus control; ${ }^{*} P<0.05$ versus ghrelin-pf.

Effects on glucose metabolism. Overall and tissue-specific insulin sensitivity was determined using insulin tolerance tests (ITTs) and euglycemic-hyperinsulinemic clamps with the labeled 2-deoxyglucose technique. During ITTs, plasma glucose levels decreased similarly in all groups, suggesting that icv ghrelin infusion did not modify overall insulin sensitivity (data not shown). This observation was consistent with similar rates of overall glucose disappearance in ghrelin- and vehicle-treated rats as determined by euglycemic-hyperinsulinemic clamps (control, $15.7 \pm 1.2 \mathrm{mg} / \mathrm{min} / \mathrm{kg}$, $n=8$; ghrelin-ad lib, $15.2 \pm 0.5 \mathrm{mg} / \mathrm{min} / \mathrm{kg}, n=8$; ghrelin-pf, $20.2 \pm 2.9 \mathrm{mg} / \mathrm{min} / \mathrm{kg}, n=9 ; P=\mathrm{NS})$. Given the fact that skeletal muscle is the main glucose-consuming tissue, the lack of ghrelininduced effect on insulin sensitivity is consistent with the absence of an effect of ghrelin on glucose uptake in various skeletal muscles with different fiber compositions (oxidative, glycolytic, or mixed; Figure 2D and Supplemental Table 1; supplemental material available online with this article; doi:10.1172/JCI25811DS1). In only one exception, red quadriceps, was glucose uptake higher in icv ghrelin-pf animals than in icv ghrelin-ad lib animals or controls (Supplemental Table 1). During the clamps, hepatic glucose production was comparably suppressed by hyperinsulinemia in all groups (data not shown).

Effects on white adipocyte metabolism. Chronic icv ghrelin infusion increased glucose uptake in both epididymal and inguinal WAT depots (Figure 2, A and B) compared with controls. Such central ghrelin-induced stimulation of insulin-dependent glucose uptake in adipose tissue was independent of hyperphagia, as it was also observed in icv ghrelin-pf animals. In a separate experiment, the impact of icv ghrelin on several key enzymes of adipocyte lipid metabolism was assessed. As depicted in Figures 3 and 4, icv ghrelin infusion markedly increased mRNA levels of the fat storage-promoting enzymes lipoprotein lipase (LPL), acetyl-CoA carboxylase $\alpha$ (ACC), fatty acid synthase (FAS), and stearoyl-CoA desaturase-1 (SCD1) in ghrelin-ad lib and ghrelin-pf animals. In contrast, the fat oxidation-promoting enzyme carnitine palmitoyl transferase $-1 \alpha($ CPT- $1 \alpha)$ was decreased in icv ghrelin-ad lib rats (Figure 3C). Low-density RNA microarrays, another method to determine

\section{Table 1}

Effects of icv ghrelin infusion on total energy expenditure and $R Q$

$\begin{array}{lcc} & \text { TEE (kcal/kg/48 h) } & \text { RQ (48-h mean) } \\ \text { Control } & 340.6 \pm 6.1 & 0.879 \pm 0.008 \\ \text { Ghrelin-ad lib } & 345.5 \pm 7.9 & 0.925 \pm 0.007^{\mathrm{A}} \\ \text { Ghrelin-pf } & 323.8 \pm 6.8 & 0.903 \pm 0.006\end{array}$

Values are mean \pm SEM of 7-8 animals per group. Rats were icv infused with either ghrelin $(2.5 \mathrm{nmol} / \mathrm{d})$ or isotonic saline (control) for 14 days. TEE, total energy expenditure, was measured over 48 hours between days 10 and 12 of infusion. $R Q$ shows the mean value over the same 48 hours. ${ }^{A} P<0.001$ versus control. $P=\mathrm{NS}$ for all other comparisons. 
Table 2

Effects of icv ghrelin infusion on plasma bioactive ghrelin, glucose, insulin, corticosterone, leptin, FFA, and TG levels

\begin{tabular}{lccccccc} 
& Ghrelin (pg/ml) & Glucose $(\mathbf{m g} / \mathbf{d l})$ & Insulin (ng/ml) & Corticosterone (ng/ml) & Leptin (ng/ml) & FFA (mmol/l) & TG (mmol/l) \\
Control & $11.7 \pm 0.7$ & $131.8 \pm 7.8$ & $3.3 \pm 1.0$ & $47.8 \pm 5.4$ & $3.0 \pm 0.4$ & $0.57 \pm 0.06$ & $2.4 \pm 0.4$ \\
Ghrelin-ad lib & $59.5 \pm 14.1^{A}$ & $124.4 \pm 6.0$ & $2.5 \pm 0.5$ & $58.7 \pm 4.9$ & $4.8 \pm 0.9$ & $0.47 \pm 0.04$ & $1.4 \pm 0.2^{\mathrm{B}}$ \\
Ghrelin-pf & $18.3 \pm 3.8$ & $138.2 \pm 4.1$ & $1.7 \pm 0.1$ & $76.4 \pm 18.8$ & $3.9 \pm 0.7$ & $0.47 \pm 0.03$ & $1.5 \pm 0.1$ \\
\hline
\end{tabular}

Values are mean \pm SEM of 6-7 animals per group. Rats were icv infused with either ghrelin for 6 days ( $2.5 \mathrm{nmol} / \mathrm{d})$ or isotonic saline (controls). Ghrelin-pf animals were fed the same amount of food as that consumed by controls. ${ }^{A} P<0.01,{ }^{B} P<0.05$ versus control. $P=$ NS for all other comparisons.

the mRNA expression of the same enzymes, produced remarkably similar results as those generated by real-time PCR, although the primers used were different in the two techniques (Supplemental Table 2). Finally, the relevance of the observed changes at the transcriptional level was also confirmed by Western blotting for FAS and SCD1 (Figure 4, C and D), showing increased protein levels under the influence of icv ghrelin.

Hepatic mRNA expression of ACC, FAS, and CPT- $1 \alpha$ was unaltered, indicating specificity of the observed effect for WAT (data not shown). However, SCD1 mRNA levels were more than doubled in the liver of both icv ghrelin-infused groups compared with controls.

Effects on brown adipocyte metabolism. As occurred in WAT, icv ghrelin infusion promoted an increase in insulin-stimulated glucose utilization in BAT independent of hyperphagia (Figure 2C). To test the hypothesis that central ghrelin administration influences energy metabolism in brown adipocytes, we determined the mRNA expression of UCP1 and UCP3 in BAT. Central ghrelin infusion markedly decreased the expression of UCP1 in both ghrelin-infused groups (Figure 5). Similar results were observed for UCP3, although the decrease in the icv ghrelin-ad lib group was at the limit to reach statistical significance.

Time course and compound specificity of CNS ghrelin-induced changes in adipocyte metabolism. In order to determine whether the observed effects of ghrelin in the CNS are of rapid onset or attenuate over time, we assessed whether acute icv injections and 14-day infusions would cause similar changes in adipocyte metabolism as occurred with 6 days of treatment. Most of the ghrelin effects present after 6 days of treatment were not observed 24 hours after an acute injection, except for LPL (Table 3). On the other hand, most of the icv ghrelin-induced effects remained significant at 14 days of treatment, again with the exception of LPL, which was normalized by this time (Table 3 ).

Effects of low-dose central ghrelin on energy balance and metabolism. We repeated our experiments with a 10 -fold lower dose of icv ghrelin $(250 \mathrm{pmol} / \mathrm{d}$ for 6 days $)$ and observed no significant effects on food intake or body weight gain nor upon the expression of ACC and FAS in epididymal WAT or of UCP1 and UCP3 in BAT with this lower dose (Supplemental Table 3). Administration of the putatively inactive form of ghrelin (des-octanoyl ghrelin, 2.5 $\mathrm{nmol} / \mathrm{d}$ for 6 days) icv had no effect on any of the parameters that were influenced by octanoyl ghrelin (i.e., food intake, body weight gain, and WAT or BAT metabolic activity; data not shown).

Possible interference of peripheral ghrelin action. Although occurring at more than 1,000-fold lower concentration than would be expected with peripheral ghrelin, CNS ghrelin-induced effects could theoretically be a consequence of leakage from the CNS into the peripheral circulation. We therefore chronically administered ghrelin peripherally under the otherwise same conditions (for 6 days via s.c. minipumps) and in the same amount as was effec- tively administered centrally $(2.5 \mathrm{nmol} / \mathrm{d})$, reflecting the maximal amount of ghrelin that could have leaked from the CNS into the periphery. As expected, we were unable to detect any effect on body weight, energy balance, or lipid or glucose metabolism (Table 4).

Possible mediating mechanism and relevance for endogenous ghrelin function. As mentioned in the Introduction, NPY is the main target of ghrelin action within the hypothalamus. In the present experiment, icv ghrelin infusion $(2.5 \mathrm{nmol} / \mathrm{d}$ for 6 days) resulted in increased hypothalamic NPY mRNA expression as expected, and this occurred even in the absence of hyperphagia (Figure 6). As central NPY is known to modulate the activity of the autonomic nervous system, specifically, to inhibit the activity of some sympathetic efferents (e.g., those innervating BAT; ref. 31), we examined central ghrelin action in the absence of sympathetic nervous system signaling. For this purpose, we treated WT and triple $\beta_{1^{-}}, \beta_{2^{-}}$, and $\beta_{3}$-adrenoceptor
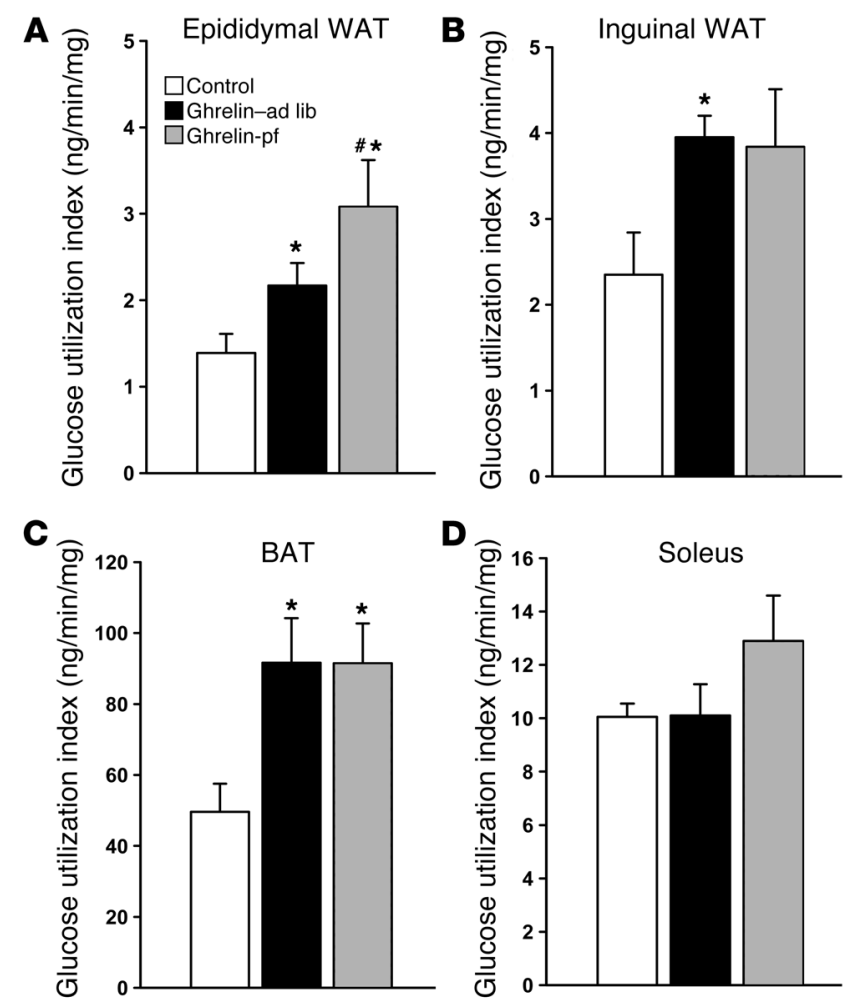

Figure 2

Effect of a 6-day icv ghrelin infusion $(2.5 \mathrm{nmol} /$ day $)$ on insulin-stimulated glucose utilization indices measured during euglycemic-hyperinsulinemic clamps in epididymal WAT (A), inguinal WAT (B), BAT (C), and soleus muscle (D). Values are mean \pm SEM of $6-7$ animals per group. ${ }^{*} P<0.05$ versus control; ${ }^{*} P<0.05$ versus ghrelin-pf. 

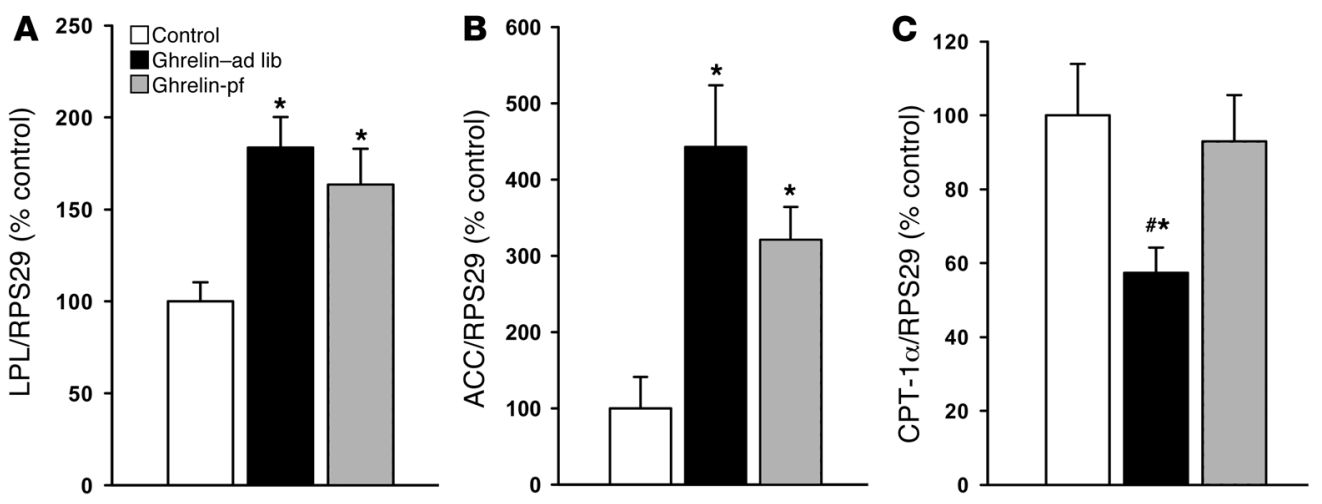

\section{Figure 3}

Effect of a 6-day icv ghrelin infusion $(2.5 \mathrm{nmol} / \mathrm{d})$ on epididymal WAT mRNA expression of LPL (A), ACC (B), and CPT-1 $\alpha$ (C). Data are presented as values normalized to RPS29, which was used as a housekeeping gene. Values are mean \pm SEM of 6-7 animals per group. ${ }^{*} P<0.05$ versus control; $\# P<0.05$ versus ghrelin-pf. knockout (TKO) mice with icv ghrelin following the same protocol as that described above $(2.5 \mathrm{nmol} / \mathrm{d}$ for 6 days). As expected, icv ghrelin administration increased body weight gain in WT animals, while identical icv ghrelin treatment in TKO animals had no effect on body weight gain (Figure 7, C and D). There was no ghrelin effect on cumulative food intake in WT or TKO mice, although there was a trend toward an increase in WT mice (Figure 7, A and B). Indicative of a possible dependence of $\mathrm{icv}$ ghrelin-induced regulation of adipocyte metabolism on the efferent sympathetic nervous system, ghrelin failed to change mRNA expression of FAS $(87.4 \% \pm 36.8 \%$ of control; values normalized by cyclophilin A, used as a reporter gene; $P=\mathrm{NS})$ and UCP1 (117.2\% $\pm 33.3 \%$ of control; values normalized by cyclophilin A, used as a reporter gene; $P=\mathrm{NS}$ ) in adipose tissue of TKO mice.

To further examine whether the abovedescribed observations are indicative of an essential endogenous role for ghrelin in the regulation of WAT metabolism, we analyzed adipocyte metabolism of ghrelin-deficient mice. Interestingly, expression patterns opposite to those observed during icv ghrelin treatment were identified, reflecting a possible physiological role of ghrelin in the control of WAT metabolism. Specifically, we observed a decrease in LPL and SCD1 mRNA expression in ghrelin $\mathrm{KO}$ mice compared with WT controls (Figure 8), while food intake, body weight, and body fat did not differ between ghrelin-deficient mice and their WT littermates, which were all on a chow diet during the whole study.

\section{Figure 4}

Effect of a 6-day icv ghrelin infusion (2.5 $\mathrm{nmol} / \mathrm{d}$ ) on epididymal WAT mRNA expression of FAS (A) and SCD1 (B), as well as on epididymal WAT FAS (C) and SCD1 (D) protein expression, with 1 representative Western blot (of the 2 performed). Data in $\mathbf{C}$ and $\mathbf{D}$ are presented as values normalized to calreticulin, which was used as a housekeeping gene. Values are mean \pm SEM of 6-7 animals per group. ${ }^{*} P<0.05$ versus control; $\# P<0.05$ versus ghrelin-pf.
$\mathbf{A}$

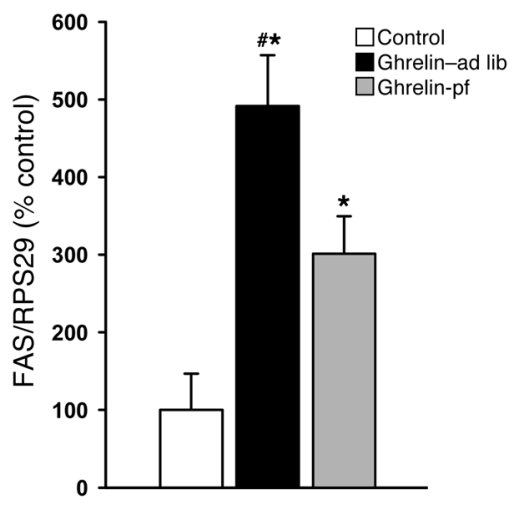

C

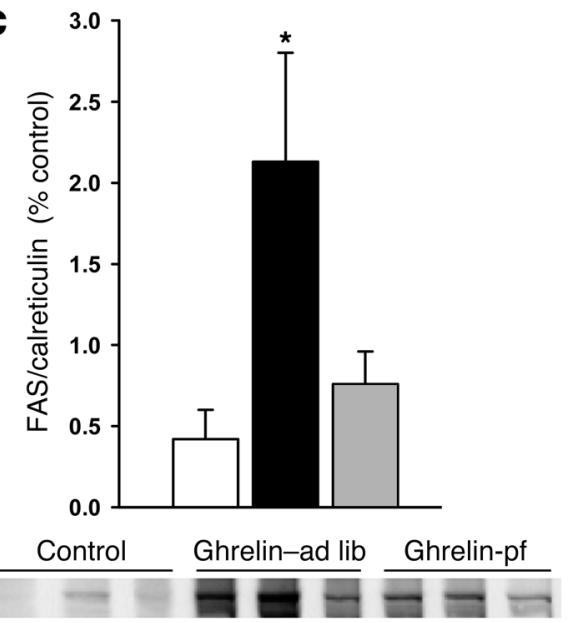

B

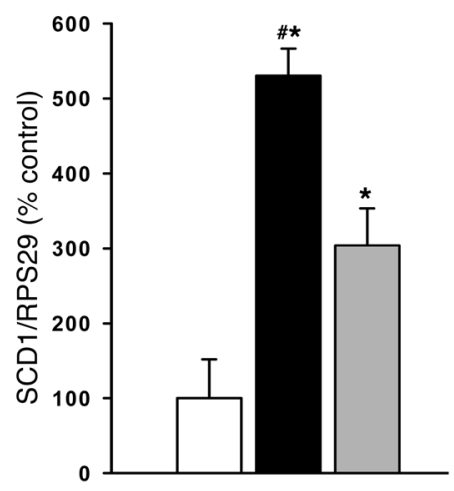

D

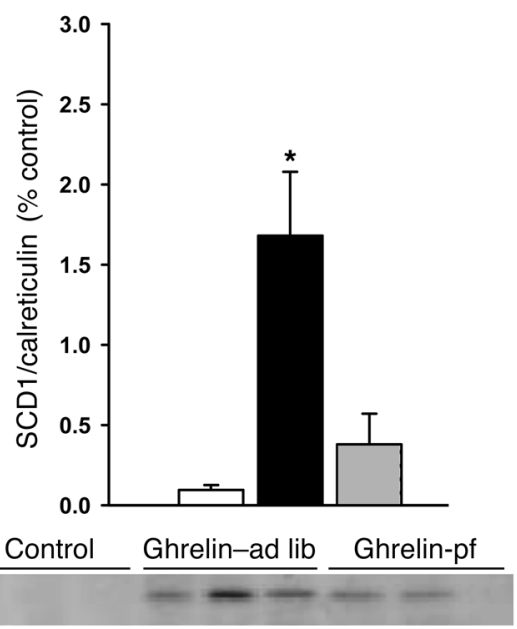



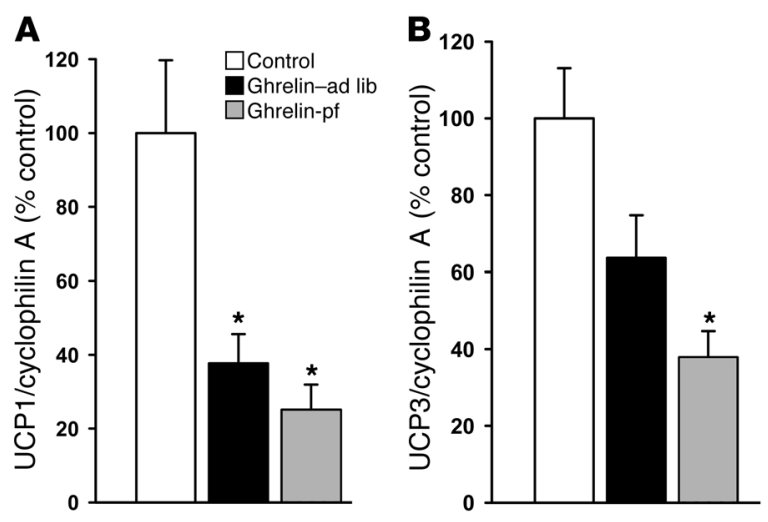

Figure 5

Effect of a 6-day icv ghrelin infusion $(2.5 \mathrm{nmol} / \mathrm{d})$ on BAT UCP1 (A) and UCP3 (B). Data are presented as values normalized to cyclophilin A, which was used as a housekeeping gene. Values are mean \pm SEM of 6-7 animals per group. ${ }^{*} P<0.05$ versus control.

ment of adiposity by decreasing fat oxidation $(14,19,26,37,38)$. More recently, a series of elegant studies based on targeted mouse mutagenesis of the genes for ghrelin or its receptor indicated an essential role for endogenous ghrelin regarding the effective deposition of excess dietary fat $(21,22)$. Ghrelin synthesis was observed within the mediobasal hypothalamus, although this observation is controversial and its functional relevance is not entirely clear $(15-18,29)$. Nevertheless, the ghrelin receptor GHSR-1 is expressed centrally, and in the hypothalamus ghrelin activates NPY/AgRP-coexpressing neurons to mediate its orexigenic effects $(12,39,40)$. Here we report that central ghrelin action increased food intake and independently regulated adipocyte metabolism. Thus central ghrelin action channels nutrient partitioning toward fat storage by favoring glucose and TG uptake, by increasing lipogenesis, and by inhibiting lipid oxidation in white adipocytes. In BAT, icv ghrelin decreased the expression of UCPs, which usually contribute to energy dissipation. These data are consistent with a report of decreased BAT sympathetic activity and lowered BAT temperature (41) as well as lowered body core temperature (42) in response to central ghrelin administration.

Most changes observed in the ghrelin-ad lib group also occurred in ghrelin-pf animals, although not always as robustly. This implies that the observed metabolic changes were due to increased ghrelin action per se, rather than being secondarily caused by the ghrelin-induced increase in food intake. However, it appears that in order to achieve its full potency as a fat storage-promoting factor, ghrelin needs to affect both nutrient intake and metabolic nutrient partitioning, since the most significant ghrelin-induced body fat gain occurs upon combination of ample substrate availability, strong orexigenic drive, and high efficiency for lipid storage.

We also observed that chronic infusion of ghrelin directly into the CNS did not decrease spontaneous activity levels of caged rats, as we previously

\section{Table 3} SCD1 in epididymal WAT reported following acute ghrelin injections (43). We speculate that, similar to numerous other neuroendocrine pathways, pulses of ligand concentration changes are much more important for the control of a particular effect or behavior than chronic ligand concentration changes caused by constant infusion. Ongoing studies in our laboratory indicate that it is difficult to determine the exact impact of activity-associated changes in thermogenesis on the overall energy balance, since that parameter is influencing and influenced by other energy balance components such as feeding behavior, nutrient partitioning, and cellular resting thermogenesis. Furthermore, activity changes induced by neuroendocrine factors vary with the quantification method (cage activity, voluntary wheel running, open field test) and the environment (diet, light cycle, ambient temperature).

Another important observation of the present study is that none of the central ghrelin effects on adipocyte metabolism were observed following peripheral administration of equal amounts of ghrelin, indicating that ghrelin action is elicited within the brain. This suggests the possibility that stomach-derived ghrelin, if secreted in substantial amounts, acts at the level of brain structures such as the hypothalamus to affect peripheral adipocyte metabolism. This in contrast with other data (44) showing that chronic peripheral ghrelin infusion in rats influenced the expression of enzymes involved in lipogenesis, gluconeogenesis, and lipid oxidation, mostly in the liver and skeletal muscle. This resulted in an increase and a decrease in lipid deposition in the liver and in mixed skeletal muscle, respectively. Although these results were obtained upon peripheral ghrelin treatment (44), it cannot be ruled out that they were elicited by central ghrelin action, since the peripheral doses administered would have allowed for significant impact on hypothalamic receptors. Our present study focused on icv ghrelin effects on adipose tissue, and the results suggest that central ghrelin may "prime" this tissue to store energy as fat by altering adipocyte enzyme expression. In this context, it could be speculated that the well-known pre-meal peaks of circulating ghrelin are triggering meal preparation processes in the CNS, rather than actually initiating meals.

While pharmacological experiments based on the administration of synthetic ghrelin to animal models are providing important insight into principal effects, targets, and mechanisms of ghrelin action, understanding the function of endogenous ghrelin requires more sophisticated approaches such as genetic disruption of the ghrelin gene. Wortley and colleagues reported earlier (29) that mice deficient for the ghrelin gene exhibit a decreased RQ

Effects of acute and chronic icv ghrelin infusion on mRNA expression of LPL, ACC, FAS, and

\begin{tabular}{lccccc} 
& & LPL (\% control) & ACC (\% control) & FAS (\% control) & SCD1 (\% control) \\
Acute & Control & $100 \pm 28$ & $100 \pm 25$ & $100 \pm 26$ & $100 \pm 35$ \\
\multirow{4}{*}{ Chronic } & Ghrelin & $209 \pm 44^{\mathrm{A}}$ & $184 \pm 21$ & $79 \pm 31$ & $185 \pm 48$ \\
& Control & $100 \pm 26$ & $100 \pm 14$ & $100 \pm 33$ & $100 \pm 55$ \\
& Ghrelin-ad lib & $97 \pm 21$ & $446 \pm 141^{\mathrm{A}}$ & $483 \pm 196^{\mathrm{A}}$ & $502 \pm 208^{\mathrm{A}}$ \\
& Ghrelin-pf & $88 \pm 29$ & $579 \pm 206^{\mathrm{A}}$ & $556 \pm 164^{\mathrm{A}}$ & $474 \pm 148^{\mathrm{A}}$ \\
\hline
\end{tabular}

Values are mean \pm SEM of 6-8 animals per group. In the acute experiment, rats were icv injected with a single bolus of ghrelin $(3 \mathrm{nmol})$ or isotonic saline (controls) over 24 hours. In the chronic experiment, animals were infused icv with ghrelin $(2.5 \mathrm{nmol} / \mathrm{d})$ or isotonic saline (controls) for 14 days. ${ }^{A} P<0.05$ versus control. $P=$ NS for all other comparisons. 


\section{Table 4}

Effects of peripheral ghrelin infusion on mRNA expression of ACC, FAS, SCD1, LPL, and CPT-1 $\alpha$ in epididymal WAT and UCP1 and UCP3 in BAT

\begin{tabular}{lccccccc} 
& ACC (\% control) & FAS (\% control) & SCD1 $(\%$ control) & LPL (\% control) & CPT- $1 \alpha(\%$ control) & UCP1 (\% control) & UCP3 (\% control) \\
Control & $100 \pm 11$ & $100 \pm 15$ & $100 \pm 27$ & $100 \pm 29$ & $100 \pm 40$ & $100 \pm 26$ & $100 \pm 33$ \\
Ghrelin & $98 \pm 21$ & $74 \pm 24$ & $82 \pm 13$ & $98 \pm 18$ & $87 \pm 6$ & $84 \pm 31$ & $75 \pm 28$ \\
\hline
\end{tabular}

Values are mean \pm SEM of 6-7 animals per group. Rats were infused s.c. with either ghrelin for 6 days (2.5 nmol/d) or isotonic saline (control). Ghrelininfused animals were fed ad libitum. $P=$ NS for all comparisons.

indicating decreased fat deposition. Here we report possible molecular explanations for such observations. The markedly decreased expression of lipogenic enzymes in WAT of ghrelin KO mice we observed in the present study may be the explanation for both their decreased RQ and their significantly decreased efficiency in storing lipids when chronically exposed to a high-fat diet (21). We propose that on a normal chow diet, the limited lipogenic pathway activity of ghrelin $\mathrm{KO}$ mice is sufficient to maintain a physiological phenotype, while under conditions of abundant dietary fat, the impaired adipocyte metabolism becomes functionally relevant and leads to decreased susceptibility for diet-induced obesity.

The ghrelin-elicited effects observed in the present study have analogies with those reported in response to central NPY administration. Thus central (icv, intra-paraventricular nuclear, or intra-sulcal prefrontal cortex) NPY injections or continuous infusions were shown to result in increased lipogenesis, increased WAT glucose utilization, and increased ACC and LPL activity while promoting decreased thermogenesis and decreased BAT UCP1 mRNA expression $(8,45-48)$. These changes were observed whether icv NPY-treated rats were fed ad libitum or were pair-fed $(8,46,47)$, and an actual increase in body weight occurred only when hyperphagia was allowed (8). However, in contrast to the effects of ghrelin reported here, chronic (i.e., 6-7 days) continuous icv NPY infusion also resulted in hyperinsulinemia, hypercorticosteronemia, and muscle insulin resistance $(9,49)$. The absence of hyperinsulinemia in ghrelin-infused animals may partly explain the lack of change in muscle insulin sensitivity. Indeed, it has been reported that plasma insulin levels correlate with the degree of muscle insulin resistance (50), and that when chronic hyperinsulinemia is imposed on normal rats, it downregulates muscle GLUT4 mRNA and protein expressions (51). The absence of significant hypercorticosteronemia observed in ghrelin-infused rats may be another explanation for the absence of muscle insulin resistance in these animals, as glucocorticoids, whether administered centrally or peripherally, powerfully decrease overall glucose utilization rates $(52,53)$.

The observation that icv ghrelin-infused rats failed to become hyperinsulinemic, even when they were hyperphagic, is of interest and suggests that ghrelin may inhibit a food-induced insulin response. This is partly supported by previous reports that ghrelin exerts a direct inhibitory effect on insulin secretion, as determined in isolated rat islets, INS-1E cells, and humans following i.v. ghrelin injection $(54,55)$.

Such a direct effect of ghrelin on insulin release could be one of the underlying mechanisms by which icv ghrelin-ad lib rats fail to display hyperinsulinemia in response to hyperphagia. Indeed, we observed that plasma levels of bioactive ghrelin were increased in the icv ghrelin-ad lib group, while such an increase was absent in the icv ghrelin-pf group. The reason why such an increase was not observed in ghrelin-pf animals is unclear and warrants further investigation. Leakage of ghrelin into the peripheral circulation is unlikely, as it should have occurred in both icv ghrelin-infused groups regardless of the feeding paradigm used. An impact of central ghrelin infusion on gastric ghrelin synthesis is also unlikely, due to the observation that gastric ghrelin mRNA expression was unaltered in both groups of icv ghrelin-infused rats. Thus the increased bioactive plasma ghrelin levels observed in the ad libitum feeding condition could result from altered ghrelin clearance and/ or octanoylation rate. While this phenomenon will be studied in more detail in future experiments, we have excluded the possibility that increased peripheral ghrelin levels contribute to the observed effects by showing that peripheral infusion of amounts identical to those administered centrally failed to trigger any effects.

Concerning the mechanisms by which central ghrelin infusion modulates adipocyte metabolism, several lines of evidence suggested a role of the autonomic nervous system. It is known that ghrelin increases gastric acid secretion by activating the vagus system (56) while decreasing BAT sympathetic activity (41). Similar effects were reported in response to central NPY administration $(31,57,58)$. As the central ghrelin effects reported in our study were measured in WAT and BAT, tissues that are mostly innervated by the sympathetic nervous system (59-61), we tested the hypothesis that this system is a mediator of central ghrelin action. For this purpose, central ghrelin administration was carried out in WT mice and in previously described TKO animals $(62,63)$. Our results indicate that intact $\beta$-adrenergic signaling is required for the ghrelin-induced increase in body weight gain. Preliminary data also indicate that ghrelininduced changes in adipocyte metabolism fail to occur in TKO mice (our unpublished observations). While these observations point to a possibly essential role of the sympathetic nervous system in the central control of adipocyte metabolism, such massive disruption of the signaling of the entire sympathetic nervous system represents an artificial situation. Future pharmacological, surgical, and

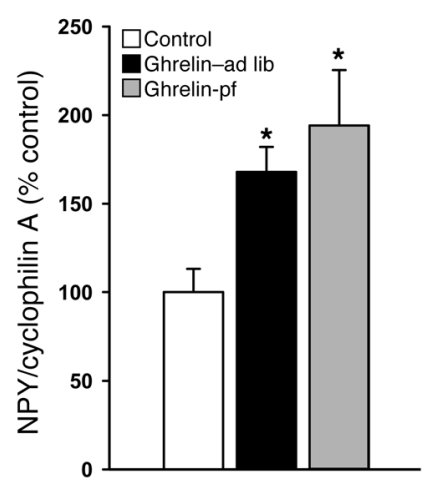

\section{Figure 6}

Effect of a 6-day icv ghrelin infusion $(2.5 \mathrm{nmol} / \mathrm{d})$ on hypothalamic NPY mRNA expression. Values are mean \pm SEM of $6-7$ animals per group. ${ }^{\star} P<0.05$ versus control. 
A
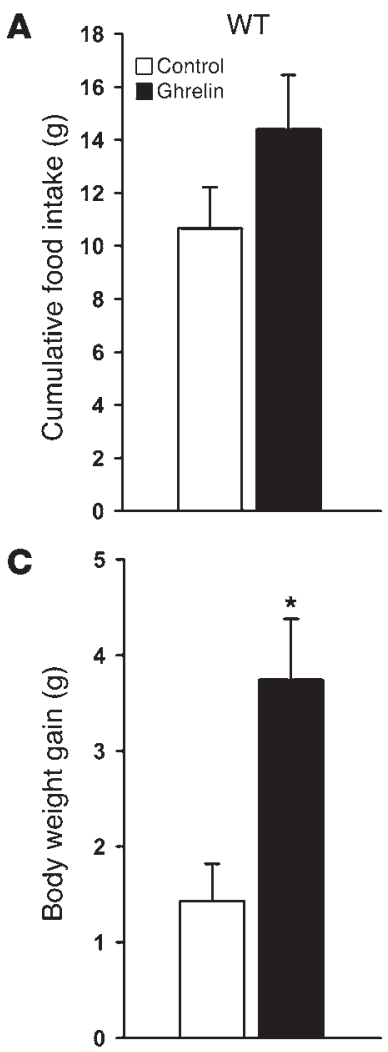

B
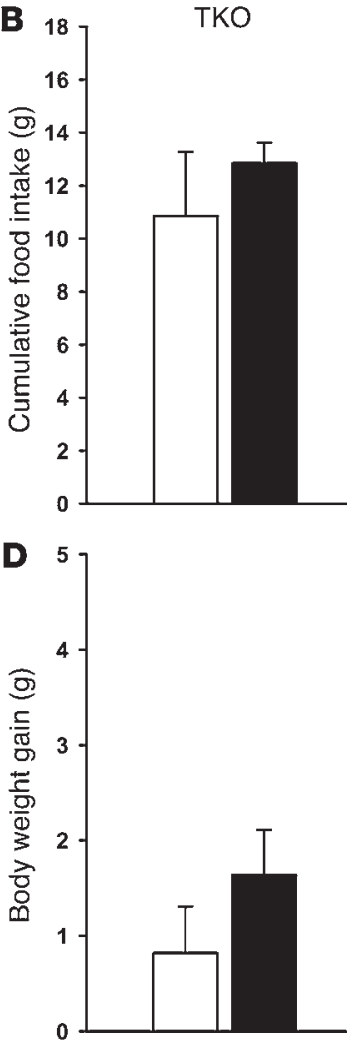

Figure 7

Effect of a 6-day icv ghrelin infusion $(2.5 \mathrm{nmol} /$ day $)$ on cumulative food intake (A and $\mathbf{B}$ ) and body weight gain ( $\mathbf{C}$ and $\mathbf{D}$ ) in WT and TKO mice. Values are mean \pm SEM of $5-6$ animals per group. ${ }^{*} P<0.05$ versus control.

genetic studies are required to further dissect the detailed molecular underpinnings of the complex processes responsible for a direct central control of white adipocyte metabolism.

In summary, we demonstrate here that a neuroendocrine network in the CNS involving ghrelin, its hypothalamic target neurons, and the sympathetic nervous system directly regulated energy metabolism in adipocytes. This phenomenon is intriguingly analogous to the recently emerging demonstration of hypothalamic control of hepatic glucose metabolism $(3,4)$. The physiological relevance of such neuroendocrine control of adipocyte metabolism is suggested by the observation that ghrelin-deficient mice exhibit defective regulation of lipid-metabolizing enzymes, which could at least partly explain their impaired nutrient partitioning and inefficient lipid deposition. Specifically, we hypothesize that their significant, although moderate, enzymatic deficiency still provides enough lipid storage capacity to manage the low amount of nutritional lipids ingested with the normal chow diet. However, on a high-fat diet (21), the enzymatic capacity of ghrelin KO mice may become the limiting factor for storing fat from circulating lipids, thereby contributing to the protection against diet-induced obesity observed in ghrelin KO mice (21). Finally, the observed changes in LPL, ACC, FAS, SCD1, CPT-1 $\alpha$, UCP1, and UCP3 mRNA expression during central ghrelin infusion may serve as valid endpoints for the development of potent receptor agonists and antagonists that may prove to be of potential therapeutic value.

\section{Methods}

Experiments. Five main types of experiments were conducted, each of which was designed to answer a specific aspect of the questions posed. Some of these experimental types were subdivided into different series of studies. All but the experiment designed to determine the ghrelin effect on glucose metabolism ended by killing the animals by decapitation, collecting trunk blood and samples of various tissues, and storing at $-80^{\circ} \mathrm{C}$ until further processing for the measurement of hormones, metabolites, and tissue-specific mRNA or protein expression of various enzymes.

To investigate acute effects of icv ghrelin on adipocyte metabolism, rats were sacrificed 24 hours after a single injection of $5 \mu \mathrm{l}$ of either saline or $3 \mathrm{nmol}$ ghrelin.

To assess chronic (i.e., 6-14 days) effects of icv ghrelin, 4 different studies were performed. The first study aimed at investigating the effects of icv ghrelin infusion $(2.5 \mathrm{nmol} / \mathrm{d}$ for 6 days) on overall and tissue-specific glucose utilization rates during euglycemic-hyperinsulinemic clamps. Two additional studies were designed to measure mRNA expression of enzymes involved in lipid metabolism and thermogenesis-related processes following the icv infusion of $2.5 \mathrm{nmol} / \mathrm{d}$ or $250 \mathrm{pmol} / \mathrm{d}$ ghrelin for 6 days. In the fourth study, rats were treated icv with either saline or ghrelin $(2.5 \mathrm{nmol} / \mathrm{d})$ for a period of 14 days. During the treatment rats were analyzed for food intake, energy expenditure, RQ, and locomotor activity using a custommade 32-cage calorimetry system (LabMaster; TSE Systems).

To test whether the observed effects could be mediated by peripheral ghrelin leaking out of the brain, we infused rats s.c. with either saline or ghrelin $(2.5 \mathrm{nmol} / \mathrm{d})$ for a 6 -day period using minipumps.

To investigate the impact of the sympathetic nervous system on ghrelin effects on adipocyte metabolism, TKO mice and WT controls were infused icv with ghrelin $(2.5 \mathrm{nmol} / \mathrm{d}$ for 6 days).

To determine the physiological relevance of ghrelin effects on adipocyte metabolism, analysis of mRNA expression of lipid-metabolizing enzymes was carried out in adipose tissue of ghrelin $\mathrm{KO}$ mice.

Animals. For all experiments of icv and peripheral ghrelin administration, 8- to 10-week-old, 300- to 400-g male Wistar rats purchased from Charles River Laboratories or from Harlan were housed in individual cages under conditions of controlled temperature $\left(23^{\circ} \mathrm{C}\right)$ and illumination (12-hour light/12-hour dark cycle). They were allowed ad libitum access to water and standard laboratory chow (RMI, Special Diet Services; ssniff RM/H; Ssniff Spezialdiäten GmbH; Harlan Teklad), unless otherwise stated.

Three- to 4-month-old WT and TKO mice were obtained as previously described (63). Briefly, $\beta_{1}{ }^{+/-} \beta_{2}{ }^{+/-} \beta_{3}{ }^{+/-}$mice were crossed to generate $\beta_{1}{ }^{+/+} \beta_{2}{ }^{+/+} \beta_{3}{ }^{+/+}$and $\beta_{1}-/-\beta_{2}-/-\beta_{3}^{-/-}$mice. Several couples were then estab-
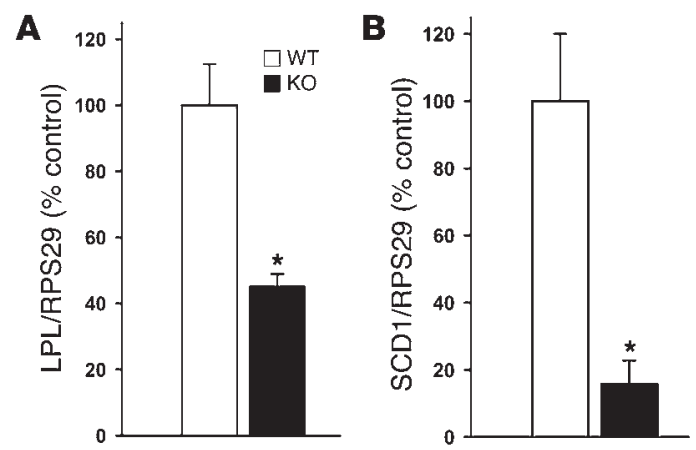

Figure 8

Epididymal WAT mRNA expression of LPL (A) and SCD1 (B) in WT and ghrelin $\mathrm{KO}$ mice. Values are mean \pm SEM of 5 animals per group. ${ }^{*} P<0.05$ versus WT. 


\section{Table 5}

Primer sequences used for real-time RT-PCR

\begin{tabular}{|c|c|c|c|c|c|}
\hline Gene & Accession & Forward & Reverse & Product & Annealing \\
\hline NPY & M15880 & 5'-GACCCTTCCATGTGGTGATG-3' & 5'-AGGCAGACTGGTTTCACAGG-3' & 96 & 55 \\
\hline ACC & J03808 & 5'-TCCGGCTTGCACCATGATAA-3' & 5'-CCCCCAAAACGAGTAACAA-3' & 104 & 54 \\
\hline FAS & M76767 & 5'-AGGATGTCAACAAGCCCAAG-3' & 5'-ACAGAGGAGAAGGCCACAAA-3' & 100 & 55 \\
\hline SCD1 & AF509569 & 5'-TGAAAGCTGAGAAGCTGGTG-3' & 5'-CAGTGTGGGCAGGATGAAG-3' & 83 & 57 \\
\hline LPL & L03294 & 5'-TCTCCTGATGATGCGGATTT-3' & 5'-CAACATGCCCATCTGGTTTC-3' & 97 & 54 \\
\hline CPT-1 $1 \alpha$ & L07736 & 5'-GGATGGCATGTGGGTAAAAG-3' & 5'-TACTGACACAGGCAGCCAAA-3' & 203 & 55 \\
\hline UCP1 & M11814 & 5'-GCCTCTACGATACGGTCCAA-3' & 5'-TGCATTCTGACCTTCACCAC-3' & 145 & 55 \\
\hline UCP3 & AB006614 & 5'-TTCTACACCCCCAAAGGAAC-3' & 5'-AATCGGACCTTCACCACATC-3' & 119 & 55 \\
\hline Ghrelin & AB29433 & 5'-CCAAGAAGCCACCAGCTAAA-3' & 5'-CTGATTTCCAGCTCCTCCTC-3' & 103 & 59 \\
\hline Cyclophilin A & M19533 & 5'-AGCACTGGGGAGAAAGGATT-3' & 5'-CATGCCTTCTTTCACCTTCC-3' & 291 & 55 \\
\hline Cyclophilin B & NM022536 & 5'-GAGACTTCACCAGGGG-3' & 5'-CTGTCCGTCTTGGTGTTCTCC-3' & 252 & 55 \\
\hline RPS29 & X59051 & 5'-GCTGAACATGTGCCGACAGT-3' & 5'-GGTCGCTTAGTCCAACTTAATGAAG-3' & 73 & 58 \\
\hline
\end{tabular}

lished from these homozygous mice at the University of Geneva, and experiments were performed on $\beta_{1}{ }^{+/+} \beta_{2}{ }^{+/+} \beta_{3}{ }^{+/+}$(WT) and $\beta_{1}{ }^{-/-} \beta_{2}{ }^{-/-} \beta_{3}{ }^{-/-}$ (TKO) offspring.

Adult ghrelin gene-disrupted mice, which were originally kindly provided by Regeneron Pharmaceuticals, originated from an in-house breeding colony of our laboratory at the University of Cincinnati. Male mice (30-35 g) were maintained under conditions of controlled temperature $\left(22.5^{\circ} \mathrm{C}\right)$ and illumination (12-hour light/12-hour dark cycle).

Food intake and body weight were measured daily during the experimental phase in all experiments.

Depending on where the experiment was performed, the procedures were approved either by the Office Vétérinaire Fédéral et Cantonal (Geneva, Switzerland); the federal guidelines of Brandenburg Ministry for Rural Development, Environment and Consumer Protection (Potsdam, Germany); or the University of Cincinnati Institutional Animal Care and Use Committee in accordance with the NIH guide for the care and use of laboratory animals.

Intracerebroventricular infusions. For experiments of acute and chronic icv ghrelin treatment, animals were anesthetized with intramuscular ketamine-xylazine used at 50-80 and 9-13 mg/kg, respectively (Pfizer and Bayer), and equipped with a cannula positioned in the right lateral cerebral ventricle (icv) fixed on the skull with dental cement, as previously described (64). Following surgery, the animals received a single dose of s.c. $0.28 \mathrm{mg} / \mathrm{kg}$ buprenorphin (Buprenex; Reckitt Benckiser Healthcare). After 1 week of recovery, acute icv injections of $5 \mu \mathrm{l}$ of either saline or ghrelin $(3 \mathrm{nmol})$ were performed using an injector cannula (Plastics One Inc.) connected via a polyethylene catheter to a 20- $\mu$ l Hamilton syringe. For chronic experiments, s.c. implanted osmotic minipumps (Alzet Osmotic Pumps; DURECT) delivering ghrelin (Bachem) or its vehicle (isotonic saline) were connected to the icv infusion cannula via a polyethylene catheter (64).

Ghrelin was infused icv at concentrations of either $250 \mathrm{pmol}$ or $2.5 \mathrm{nmol}$ per day for 6 or 14 days. At a dose of $2.5 \mathrm{nmol} / \mathrm{d}$, ghrelin infusion has been reported to increase food intake and body weight gain (19). To differentiate between ghrelin effects per se from those related to increased food intake, a group of ghrelin-treated rats was prevented from overeating by pair-feeding them to the amount of food consumed by controls (ghrelin-pf). During the 6-day icv treatment, the pair-feeding regimen consisted in giving one-third of the daily food amount in the morning and the remaining two-thirds just before onset of darkness. During the 14-day treatment, pair-fed rats received the daily amount of food prior to the onset of darkness.

Thus most of the experiments included 3 groups of animals: an ad libitum-fed control group infused with icv saline and $2 \mathrm{icv}$ ghrelin-infused groups, ghrelin-ad lib and ghrelin-pf. For the 6-day peripheral treatment, only the saline and ghrelin-ad lib animals were monitored.

Energy expenditure, locomotor activity, $R Q$ and lipid utilization. During the icv treatment for the period of 14 days, rats were analyzed for energy expenditure, $\mathrm{RQ}$, and locomotor activity using a custom-made 32-cage calorimetry system (LabMaster; TSE Systems). The instrument consists of a combination of highly sensitive feeding and drinking sensors for automated online measurement. The calorimetry system is an open-circuit system that determines $\mathrm{O}_{2}$ consumption, $\mathrm{CO}_{2}$ production, and RQ. A photobeam-based activity monitoring system detects and records every ambulatory movement, including rearing and climbing movements, in every cage. Detection of animal location is performed with infrared sensor pairs arranged in strips for horizontal ( $x, y$ level) and vertical ( $z$ level, rearing) activity. The sensors for detection of movement operate efficiently in both light and dark phases, allowing continuous recording. All the parameters can be measured continuously, simultaneously, and in up to 32 animals. The rats (7-8 per group) were placed in the calorimetry system cages on day 8 of treatment. After 48 hours of adaptation, data were collected in the next 48 hours, and the animals were returned to standard cages.

Body composition was measured in rats infused icv with ghrelin for 14 days using NMR imaging (Whole Body Composition Analyzer; EchoMRI). Measurements were performed before surgery and prior to sacrifice at the end of the treatment period.

Euglycemic-byperinsulinemic clamps. After 6 days of icv ghrelin or saline treatment, rats were fasted for 12 hours, were anesthetized with sodium pentobarbital $(55 \mathrm{mg} / \mathrm{kg})$ given i.p., and underwent a euglycemic-hyperinsulinemic clamp as previously described (65). The rates of total glucose utilization (rate of glucose disappearance) and of hepatic glucose production (rate of glucose appearance) were determined via an infusion of D-[U- $\left.{ }^{14} \mathrm{C}\right]$ glucose (0.407 MBq per rat; Amersham Biosciences), according to a method previously described (65). At the end of these euglycemic-hyperinsulinemic clamps, a bolus of 2-deoxy-D-[1- $\left.{ }^{3} \mathrm{H}\right]$ glucose (1.11 MBq per rat; Amersham Biosciences) was injected i.v. to determine the in vivo insulin-stimulated glucose utilization indices of various muscle types, WAT, and BAT $(66,67)$. The tissues were stored at $-80^{\circ} \mathrm{C}$ until further analysis.

Analytical procedures related to the clamp studies. We determined 2-deoxy-D- $\left[1-{ }^{-} \mathrm{H}\right]$ glucose- and $\mathrm{D}-\left[\mathrm{U}-{ }^{14} \mathrm{C}\right]$ glucose-specific activities in deproteinized blood samples as previously reported $(66,67)$. Measurement of tissue concentrations of 2-deoxy-D-[1- $\left.{ }^{3} \mathrm{H}\right]$ glucose- 6 -phosphate allowed to calculate the in vivo glucose utilization index by individual tissues, as $\mathrm{ng} / \mathrm{min} / \mathrm{mg}$ tissue $(66,67)$.

Quantitative RT-PCR procedure. Animals were killed by decapitation in the fed state (1-4 hours after morning feeding) and various tissues were sam- 
pled, freeze-clamped, and stored at $-80^{\circ} \mathrm{C}$ for subsequent measurement of mRNA expression of LPL, ACC, FAS, SCD1, CPT-1 $\alpha$, UCP1, UCP3, ghrelin, NPY, cyclophilin A, cyclophilin B, and RPS29 by real-time quantitative PCR (Lightcycler; Roche Diagnostics).

Total RNA was extracted from frozen tissue samples using TRIzol Reagent (Invitrogen Corp.). RNA integrity was assessed by performing a $1 \%$ agarose gel electrophoresis in $1 \times$ Tris-borate-EDTA, and its concentration was determined by spectrophotometry. cDNA templates for RT-PCR were obtained using $2.5 \mu \mathrm{g}$ of total RNA. Reverse transcription reaction was performed with random hexamers (Microsynth), dNTPs, RNAse inhibitor, Rnasin (Catalys; Promega), and the M-MLV-RT enzyme kit (Invitrogen Corp.).

Amplification of cDNAs was performed with the SYBR Green I DNA master kit (Roche Diagnostics), according to the light cycler standard protocol, using around $70 \mathrm{ng}$ template cDNA. All primers were used at a final concentration of $0.5 \mu \mathrm{M}$. After each run, a relative quantification of the amplified PCR product in the different samples was performed. This was based on the relative comparison of the PCR products during the log-linear phase of the amplification process. A standard curve was used to obtain the relative concentration of the target gene, and the results were corrected according to the concentration of cyclophilin A, cyclophilin B, or RPS29, used as housekeeping genes. The results are expressed as percent of controls, setting the mean of the control group at $100 \%$ and then calculating each individual value of the 3 groups of animals studied.

Primer sequences. Primers for rat LPL, ACC, FAS, SCD1, CPT-1 $\alpha$, ghrelin, NPY, UCP1, UCP3, cyclophilin A, cyclophilin B, and RPS29 were designed online with the web-based Primer 3 software (http://frodo.wi.mit.edu/ cgi-bin/primer3/primer3_www.cgi) and synthesized by Microsynth. The sequence and main characteristics of the primers used are provided in Table 5. The adequacy of the different PCR products was verified by nucleic acid sequencing and agarose gel electrophoresis.

Low-density array. Gene expression levels in rat WAT were also assessed by 2 -step quantitative real-time RT-PCR using the TaqMan Low Density Arrays (Applied Biosystems). The cDNA from rat WAT was obtained as described above. The relative expression of ACC, FAS, LPL, and CPT- $1 \alpha$ in our tissue samples was measured in duplicates using specific sets or primers and fluorescent TAMRA probes (Acac Rn00573474 m1, Fasn Rn00569117 m1, Lpl Rn00561482 m1, and Cpt1a Rn00580702 m1, respectively; Applied Biosystems) during the log-linear phase of a PCR reaction with the $7600 \mathrm{HT}$ TaqMan Fast Real-Time PCR System (Applied Biosystems) using Sequence Detection Software, version 2.2. The PCR reactions took place within $2-\mu l$ wells previously loaded with the specific primers and probes by the manufacturer into each of the 384 wells of the reaction card. The reaction was performed using a final cDNA sample concentration of $0.8 \mathrm{ng} / \mu \mathrm{l}$ with the TaqMan Universal PCR Master Mix (Applied Biosystems) containing the AmpliTaq Gold DNA Polymerase enzymes (Applied Biosystems), the nucleotides and the ROX fluorescent dye used as a passive load reference.

The sequences of primers and probes used were designed and validated by Applied Biosystems and were taken from the Assay-on-Demand rat library.

The relative expression levels of each gene were normalized by the geometric average of 2 control genes: RPS29 and ACRP30. These genes were statistically reported as the most stable genes measured in our experimental conditions by the statistical software geNorm (version 3.3; http://medgen. ugent.be/ jvdesomp/genorm/).

Western blot analysis. Samples ( 300 mg) of epididymal WAT were homogenized in ice-cold RIPA buffer $(100 \mathrm{mM}$ Tris $\mathrm{HCl}$; $300 \mathrm{mM} \mathrm{NaCl}$; $0.2 \%$ SDS; $1 \%$ deoxycholate; $2 \%$ NP-40; complete EDTA free, 1 tablet $/ 50$ $\mathrm{ml}, \mathrm{pH}$ 7.4) using a plastic-glass tissue grinder. Protein concentrations were determined by BCA protein assay kit (Pierce Biotechnology). Protein $(15 \mu \mathrm{g})$ from each sample was fractionated by $10 \%$ SDS-PAGE and transferred onto nitrocellulose membranes. The membranes were blocked with $0.5 \mu \mathrm{g} / \mu \mathrm{l}$ polyvinyl alcohol for 1 minute, then incubated overnight at $4{ }^{\circ} \mathrm{C}$ with one of the following antibodies: mouse monoclonal anti-FAS antibody (BD Biosciences) at a dilution of 1:250, goat polyclonal antiSCD1 antibody (Santa Cruz Biotechnology Inc.) at a dilution of 1:50, or a rabbit polyclonal anti-calreticulin antibody at a dilution of 1:1,000 (kindly provided by R.A. Clark, University of Texas Health Science Center at San Antonio, San Antonio, Texas, USA) in TBS (50 mM Tris HCL, $150 \mathrm{mM}$ $\mathrm{NaCl}, \mathrm{pH} 7.5$ ) buffer containing $0.1 \%$ Tween 20 and $5 \%$ BSA. Signals were revealed by incubation with horseradish peroxidase-conjugated goat antimouse (1:2,000 dilution), goat anti-rabbit (1:3,000 dilution; Bio-Rad) or rabbit anti-goat (1:3,000 dilution; Sigma-Aldrich) antibodies for 1 hour at room temperature. Immunoreactive bands were visualized by enhanced chemiluminescence reaction (for FAS and calreticulin antibodies, LiteAblot; Euroclone; for SCD1 antibody, Super Signal West Dura; Pierce Biotechnology; Fisher Scientific International Inc.). Bands were quantified by Quantity One System (Bio-Rad). FAS and SCD1 protein amount was expressed relative to calreticulin expression.

Levels of plasma metabolites and hormones. Plasma glucose was measured by the glucose oxidase method (glucose analyzer 2; Beckman Coulter). Plasma FFA concentrations were determined using a kit from Wako; TGs were determined using a kit from bioMérieux. Plasma insulin levels were measured by a previously described RIA (68). Plasma levels of other hormones were determined by commercial RIA kits from Linco for leptin and active ghrelin and from IDS for corticosterone. These measurements were performed on samples that were collected in fed animals around 5 hours following cessation of feeding.

Statistics. Results are given as mean \pm SEM. Statistical analysis was performed using 1-way ANOVA followed by the post-hoc Tukey test. All calculations were performed using SigmaStat 3.0 (SPSS). A 2-tailed $P$ value less than 0.05 was considered statistically significant.

\section{Acknowledgments}

This work was carried out thanks to grant no. 3100A0-105889 of the Swiss National Science Foundation. It was part of the Geneva Program for Metabolic Disorders. It was also supported by the European Community (EC) FP6 funding (contract no. LSHMCT-2003-503041) for F. Rohner-Jeanrenaud and M.H. Tschöp. It should be mentioned that the publication reflects the authors' views and not necessarily those of the EC. The information in this document is provided as is and no guarantee or warranty is given that the information is fit for any particular purpose. The user thereof uses the information at its sole risk and liability. We wish to thank Marcella Klein, Sarah Mouche, Traci Kruthaupt, and Sabine Strassburg for excellent technical and scientific assistance. We wish to thank the Genomics Platform of the National Centre of Competence in Research Frontiers in Genetics program for the invaluable help in performing the low-density array experiments. Finally, we are indebted to Steve Woods, Tim Bartness, Craig Hammond, Silvana Obici, and Randy Seeley for very insightful discussions and editing of our manuscript.

Received for publication June 1, 2005, and accepted in revised form April 20, 2006.

Address correspondence to: Françoise Rohner-Jeanrenaud, Laboratory of Metabolism, Division of Endocrinology, Diabetology, and Nutrition, Centre Médical Universitaire, 1 rue Michel-Servet, 1211 Geneva 4, Switzerland. Phone: 41-22-379-54-36; Fax: 41-22-37952-60; E-mail: Francoise.Jeanrenaud@medecine.unige.ch. 
1. Akabayashi, A., Koenig, J.I., Watanabe, Y., Alexander, J.T., and Leibowitz, S.F. 1994. Galanin-containing neurons in the paraventricular nucleus: a neurochemical marker for fat ingestion and body weight gain. Proc. Natl. Acad. Sci. U. S. A. 91:10375-10379.

2. Wortley, K.E., Chang, G.Q., Davydova, Z., and Leibowitz, S.F. 2003. Peptides that regulate food intake: orexin gene expression is increased during states of hypertriglyceridemia. Am. J. Physiol. Regul. Integr. Comp. Physiol. 284:R1454-R1465.

3. Lam, T.K., et al. 2005. Hypothalamic sensing of circulating fatty acids is required for glucose homeostasis. Nat. Med. 11:320-327.

4. Obici, S., and Rossetti, L. 2003. Minireview: nutrient sensing and the regulation of insulin action and energy balance. Endocrinology. 144:5172-5178.

5. Wortley, K.E., Chang, G.Q., Davydova, Z., Fried, S.K., and Leibowitz, S.F. 2004. Cocaine- and amphetamine-regulated transcript in the arcuate nucleus stimulates lipid metabolism to control body fat accrual on a high-fat diet. Regul. Pept. 117:89-99.

6. Yun, R., et al. 2005. PVN galanin increases fat storage and promotes obesity by causing muscle to utilize carbohydrate more than fat. Peptides. 26:2265-2273.

7. Obici, S., et al. 2001. Central melanocortin receptors regulate insulin action. J. Clin. Invest. 108:1079-1085. doi:10.1172/JCI200112954.

8. Zarjevski, N., Cusin, I., Vettor, R., Rohner-Jeanrenaud, F., and Jeanrenaud, B. 1993. Chronic intracerebroventricular neuropeptide-Y administration to normal rats mimics hormonal and metabolic changes of obesity. Endocrinology. 133:1753-1758.

9. Zarjevski, N., Cusin, I., Vettor, R., Rohner-Jeanrenaud, F., and Jeanrenaud, B. 1994. Intracerebroventricular administration of neuropeptide $Y$ to normal rats has divergent effects on glucose utilization by adipose tissue and skeletal muscle. Diabetes. 43:764-769.

10. Nakazato, M., et al. 2001. A role for ghrelin in the central regulation of feeding. Nature. 409:194-198.

11. Tschop, M., Statnick, M.A., Suter, T.M., and Heiman, M.L. 2002. GH-releasing peptide-2 increases fat mass in mice lacking NPY: indication for a crucial mediating role of hypothalamic agouti-related protein. Endocrinology. 143:558-568.

12. Chen, H.Y., et al. 2004. Orexigenic action of peripheral ghrelin is mediated by neuropeptide $\mathrm{Y}$ and agouti-related protein. Endocrinology. 145:2607-2612.

13. Kojima, M., et al. 1999. Ghrelin is a growth-hormone-releasing acylated peptide from stomach. Nature. 402:656-660.

14. Kojima, M., and Kangawa, K. 2005. Ghrelin: structure and function. Physiol. Rev. 85:495-522.

15. Turek, F.W., et al. 2005. Obesity and metabolic syndrome in circadian Clock mutant mice. Science. 308:1043-1045.

16. Cowley, M.A., et al. 2003. The distribution and mechanism of action of ghrelin in the CNS demonstrates a novel hypothalamic circuit regulating energy homeostasis. Neuron. 37:649-661.

17. Hu, Z., Cha, S.H., van Haasteren, G., Wang, J., and Lane, M.D. 2005. Effect of centrally administered $\mathrm{C} 75$, a fatty acid synthase inhibitor, on ghrelin secretion and its downstream effects. Proc. Natl. Acad. Sci. U. S. A. 102:3972-3977.

18. Mozid, A.M., et al. 2003. Ghrelin is released from rat hypothalamic explants and stimulates corticotrophin-releasing hormone and arginine-vasopressin. Horm. Metab. Res. 35:455-459.

19. Tschop, M., Smiley, D.L., and Heiman, M.L. 2000. Ghrelin induces adiposity in rodents. Nature. 407:908-913

20. Dornonville de la Cour, C., et al. 2005. Ghrelin treatment reverses the reduction in weight gain and body fat in gastrectomised mice. Gut. 54:907-913.

21. Wortley, K.E., et al. 2005. Absence of ghrelin protects against early-onset obesity. J. Clin. Invest. 115:3573-3578. doi:10.1172/JCI26003.

22. Zigman, J.M., et al. 2005. Mice lacking ghrelin receptors resist the development of diet-induced obesity. J. Clin. Invest. 115:3564-3572. doi:10.1172/ JCI26002.

23. Zhang, J.V., et al. 2005. Obestatin, a peptide encoded by the ghrelin gene, opposes ghrelin's effects on food intake. Science. 310:996-999.

24. Tschop, M., et al. 2001. Circulating ghrelin levels are decreased in human obesity. Diabetes. 50:707-709.

25. Otto, B., et al. 2001. Weight gain decreases elevated plasma ghrelin concentrations of patients with anorexia nervosa. Eur. J. Endocrinol. 145:669-673.

26. Williams, D.L., and Cummings, D.E. 2005. Regulation of ghrelin in physiologic and pathophysiologic States. J. Nutr. 135:1320-1325.

27. Tschop, M., et al. 2001. Post-prandial decrease of circulating human ghrelin levels. J. Endocrinol. Invest. 24:RC19-RC21.

28. Cummings, D.E., et al. 2001. A preprandial rise in plasma ghrelin levels suggests a role in meal initiation in humans. Diabetes. 50:1714-1719.

29. Wortley, K.E., et al. 2004. Genetic deletion of ghrelin does not decrease food intake but influences metabolic fuel preference. Proc. Natl. Acad. Sci. U. S. A. 101:8227-8232.

30. Kim, M.S., et al. 2004. Chronic central administration of ghrelin reverses the effects of leptin. Int. J. Obes. Relat. Metab. Disord. 28:1264-1271.

31. Egawa, M., Yoshimatsu, H., and Bray, G.A. 1991. Neuropeptide Y suppresses sympathetic activity to interscapular brown adipose tissue in rats. Am. J. Physiol. 260:R328-R334

32. Niswender, K.D., Baskin, D.G., and Schwartz, M.W. 2004. Insulin and its evolving partnership with leptin in the hypothalamic control of energy homeostasis. Trends Endocrinol. Metab. 15:362-369.

33. Dhillo, W.S., and Bloom, S.R. 2004. Gastrointestinal hormones and regulation of food intake. Horm. Metab. Res. 36:846-851.

34. Lutz, T.A. 2005. Pancreatic amylin as a centrally acting satiating hormone. Curr. Drug Targets. 6:181-189.

35. King, P.J. 2005. The hypothalamus and obesity. Curr. Drug Targets. 6:225-240.

36. Benoit, S.C., Clegg, D.J., Seeley, R.J., and Woods, S.C. 2004. Insulin and leptin as adiposity signals. Recent Prog. Horm. Res. 59:267-285.

37. Gottero, C., et al. 2004. Ghrelin: a link between eating disorders, obesity and reproduction. Nutr. Neurosci. 7:255-270

38. Ueno, H., Yamaguchi, H., Kangawa, K., and Nakazato, M. 2005. Ghrelin: a gastric peptide that regulates food intake and energy homeostasis. Regul. Pept. 126:11-19.

39. Tannenbaum, G.S., Lapointe, M., Beaudet, A., and Howard, A.D. 1998. Expression of growth hormone secretagogue-receptors by growth hormone-releasing hormone neurons in the mediobasal hypothalamus. Endocrinology. 139:4420-4423.

40. Cowley, M.A., and Grove, K.L. 2004. Ghrelin--satisfying a hunger for the mechanism. Endocrinology. 145:2604-2606.

41. Yasuda, T., Masaki, T., Kakuma, T., and Yoshimatsu, H. 2003. Centrally administered ghrelin suppresses sympathetic nerve activity in brown adipose tissue of rats. Neurosci. Lett. 349:75-78.

42. Lawrence, C.B., Snape, A.C., Baudoin, F.M., and Luckman, S.M. 2002. Acute central ghrelin and GH secretagogues induce feeding and activate brain appetite centers. Endocrinology. 143:155-162.

43. Tang-Christensen, M., et al. 2004. Central administration of ghrelin and agouti-related protein (83-132) increases food intake and decreases spontaneous locomotor activity in rats. Endocrinology.
$145: 4645-4652$

44. Barazzoni, R., et al. 2005. Ghrelin regulates mitochondrial-lipid metabolism gene expression and tissue fat distribution in liver and skeletal muscle. Am. J. Physiol. Endocrinol. Metab. 288:E228-E235.

45. McGregor, I.S., Menendez, J.A., and Atrens, D.M. 1990. Metabolic effects of neuropeptide $Y$ injected into the sulcal prefrontal cortex. Brain Res. Bull. 24:363-367.

46. Billington, C.J., Briggs, J.E., Grace, M., and Levine, A.S. 1991. Effects of intracerebroventricular injection of neuropeptide Y on energy metabolism. Am. J. Physiol. 260:R321-R327.

47. Billington, C.J., Briggs, J.E., Harker, S., Grace, M., and Levine, A.S. 1994. Neuropeptide Y in hypothalamic paraventricular nucleus: a center coordinating energy metabolism. Am. J. Physiol. 266:R1765-R1770.

48. Levine, A.S., Jewett, D.C., Cleary, J.P., Kotz, C.M., and Billington, C.J. 2004. Our journey with neuropeptide Y: effects on ingestive behaviors and energy expenditure. Peptides. 25:505-510.

49. Sainsbury, A., et al. 1997. Chronic central neuropeptide $\mathrm{Y}$ infusion in normal rats: status of the hypothalamo-pituitary-adrenal axis, and vagal mediation of hyperinsulinaemia. Diabetologia. 40:1269-1277.

50. Le Marchand, Y., Freychet, P., and Jeanrenaud, B. 1978. Longitudinal study on the establishment of insulin resistance in hypothalamic obese mice. Endocrinology. 102:74-85.

51. Cusin, I., et al. 1990. Hyperinsulinemia increases the amount of GLUT4 mRNA in white adipose tissue and decreases that of muscles: a clue for increased fat depot and insulin resistance. Endocrinology. 127:3246-3248.

52. Guillaume-Gentil, C., Assimacopoulos-Jeannet, F., and Jeanrenaud, B. 1993. Involvement of non-esterified fatty acid oxidation in glucocorticoid-induced peripheral insulin resistance in vivo in rats. Diabetologia. 36:899-906.

53. Cusin, I., Rouru, J., and Rohner-Jeanrenaud, F. 2001. Intracerebroventricular glucocorticoid infusion in normal rats: induction of parasympatheticmediated obesity and insulin resistance. Obes. Res. 9:401-406

54. Colombo, M., Gregersen, S., Xiao, J., and Hermansen, K. 2003. Effects of ghrelin and other neuropeptides (CART, MCH, orexin A and B, and GLP-1) on the release of insulin from isolated rat islets. Pancreas. 27:161-166.

55. Broglio, F., et al. 2003. Effects of ghrelin on the insulin and glycemic responses to glucose, arginine, or free fatty acids load in humans. J. Clin. Endocrinol. Metab. 88:4268-4272.

56. Date, Y., et al. 2001. Ghrelin acts in the central nervous system to stimulate gastric acid secretion. Biochem. Biophys. Res. Commun. 280:904-907.

57. Matsuda, M., Aono, M., Moriga, M., and Okuma, M. 1991. Centrally administered NPY stimulated gastric acid and pepsin secretion by a vagally mediated mechanism. Regul. Pept. 35:31-41.

58. Geoghegan, J.G., et al. 1993. Intracerebroventricular neuropeptide $\mathrm{Y}$ increases gastric and pancreatic secretion in the dog. Gastroenterology. 105:1069-1077.

59. Bamshad, M., Aoki, V.T., Adkison, M.G., Warren, W.S., and Bartness, T.J. 1998. Central nervous system origins of the sympathetic nervous system outflow to white adipose tissue. Am. J. Physiol. 275:R291-R299.

60. Penicaud, L., Cousin, B., Leloup, C., Lorsignol, A., and Casteilla, L. 2000. The autonomic nervous system, adipose tissue plasticity, and energy balance. Nutrition. 16:903-908.

61. Bartness, T.J., Kay Song, C., Shi, H., Bowers, R.R., and Foster, M.T. 2005. Brain-adipose tissue cross talk. Proc. Nutr. Soc. 64:53-64. 
62. Bachman, E.S., et al. 2002. betaAR signaling required for diet-induced thermogenesis and obesity resistance. Science. 297:843-845.

63. Jimenez, M., et al. 2002. Beta(1)/beta(2)/beta(3)adrenoceptor knockout mice are obese and coldsensitive but have normal lipolytic responses to fasting. FEBS Lett. 530:37-40.

64. Rohner-Jeanrenaud, F., Walker, C.D., Greco-Perotto, R., and Jeanrenaud, B. 1989. Central corticotropin-releasing factor administration prevents the excessive body weight gain of genetically obese (fa/fa) rats. Endocrinology. 124:733-739.

65. Terrettaz, J., Assimacopoulos-Jeannet, F., and Jeanrenaud, B. 1986. Severe hepatic and peripheral insulin resistance as evidenced by euglycemic clamps in genetically obese $\mathrm{fa} / \mathrm{fa}$ rats. Endocrinology. 118:674-678.

66. Cusin, I., Terrettaz, J., Rohner-Jeanrenaud, F., and Jeanrenaud, B. 1990. Metabolic consequences of hyperinsulinaemia imposed on normal rats on glucose handling by white adipose tissue, muscles and liver. Biochem. J. 267:99-103.

67. Vettor, R., Zarjevski, N., Cusin, I., Rohner-Jeanrenaud, F., and Jeanrenaud, B. 1994. Induction and reversibility of an obesity syndrome by intracerebroventricular neuropeptide $\mathrm{Y}$ administration to normal rats. Diabetologia. 37:1202-1208.

68. Herbert, V., Lau, K.S., Gottlieb, C.W., and Bleicher, S.J. 1965. Coated charcoal immunoassay of insulin. J. Clin. Endocrinol. Metab. 25:1375-1384 